\title{
Erratum to: Dynamic Analysis of Perturbed Chandler Oscillations of the Earth's Pole
}

\author{
L. D. Akulenko ${ }^{a}$ and V. V. Perepelkin ${ }^{b, *}$ \\ ${ }^{a}$ Ishlinsky Institute for Problems in Mechanics, Russian Academy of Sciences, Moscow, 119526 Russia \\ ${ }^{b}$ Moscow Aviation Institute (National Research University), Moscow, 125993 Russia \\ *e-mail: vadimkin1@yandex.ru \\ Received June 15, 2020
}

DOI: $10.3103 / \mathrm{S} 0025654420020181$

The name of the second author should read V. V. Perepelkin.

The original article can be found online at https://doi.org/10.3103/S0025654418060018 